\title{
Estratégias de resolução em problemas do Campo Conceitual Aditivo: um estudo com alunos ingressantes nos Cursos de Ciências Exatas
}

\author{
Lilian Akemi Kato \\ Professora do DMA da UEM, Maringá-PR \\ lilianakemikato@gmail.com

\section{Marli Schmitt-Zanella} \\ Mestranda do PCM da UEM, Maringá-PR \\ marlischmitt@hotmail.com
}

\author{
Vanessa Kulicheski Matias dos Santos \\ Graduada em Matemática pela UEM, Maringá-PR \\ nessakulicheski@hotmail.com
}

\section{João Roberto Gerônimo}

Professor do DMA da UEM, Maringá-PR

jrgeronimo@uem.br

\section{Kleber Luciano Niro}

Graduado em Matemática pela UEM, Maringá-PR

kleber.niro@gmail.com

\section{Jusley Talita Grimes de Souza}

Graduanda em Matemática pela UEM, Maringá-PR

jusley_talita@hotmail.com

\section{Valdinei Cezar Cardoso}

Professor do DCI da UEM, Maringá-PR

v13dinei@gmail.com

\begin{abstract}
Resumo
A Teoria dos Campos Conceituais de Vergnaud foi o referencial teórico norteador desta pesquisa que teve como objetivo principal identificar os invariantes operatórios inadequados, apresentados pelos estudantes, ingressantes nos Cursos de Ciências Exatas, em problemas do Campo Conceitual Aditivo. Para tanto, os alunos responderam um teste contendo problemas das seis categorias da estrutura aditiva, que foi analisado em termos dos cálculos relacionais apresentados, e possibilitaram a identificação dos teoremas em ação mobilizados pelos estudantes. Os resultados apontam a presença de invariantes inadequados na resolução de problemas de composição, transformação e comparação, que podem prevalecer durante toda a vida escolar dos educandos, e, consequentemente, interferir nos índices de reprovação e evasão nos cursos de graduação.
\end{abstract}

Palavras-chave: Teoria dos Campos Conceituais. Estrutura aditiva. Invariantes operatórios. Ensino superior. Ciências Exatas. 


\title{
Problem solving strategies of Additive Conceptual Field: a study of student entrants in Exact Sciences courses
}

\begin{abstract}
Vergnaud's Conceptual Fields Theory was the theoretical basis of this study which aims to identify the operational invariants inappropriate presented by student entrants in Exact Sciences courses in problems of Additive Conceptual Field. For this, the students have answered a test containing problems of six categories of additive structure, which was analyzed in terms of relational calculations presented, and permitted the identification of the theorems in action mobilized by the students. The results indicate the presence of invariant inappropriate in composition, transformation and comparison problem solving, which may prevail throughout students' school life, and thus interfere in fail and evasion rates in undergraduate courses.
\end{abstract}

Keywords: Conceptual Fields Theory. Additive structure. Operational invariants. Higher education. Exact Sciences courses. 


\section{Introdução}

Este trabalho foi pautado na Teoria dos Campos Conceituais - TCC, de Gérard Vergnaud, quanto ao estudo das ações dos alunos e as condições de produção, registro e comunicação durante situações de aprendizagem.

Trata-se de um conhecimento sobre o conteúdo a ser ensinado e das relações deste com as atividades que os educandos são capazes de realizar. Esta teoria foi, inicialmente, elaborada para explicar o processo de conceitualização progressiva das estruturas aditivas e multiplicativas.

Esta pesquisa centra-se no Campo Conceitual Aditivo, por entendermos que os conceitos, que o constituem, fornecem as bases do raciocínio envolvidas no processo de aprendizagem da Matemática.

O objetivo deste estudo foi identificar os invariantes operatórios inadequados, apresentados pelos estudantes, ingressantes nos Cursos de Ciências Exatas, em problemas do Campo Conceitual Aditivo.

Segundo Vergnaud (2009b), é por meio de suas ações que o estudante regula sua conduta sobre as relações que ele apreende e sobre o cálculo relacional que faz. Nesse sentido, em nosso trabalho, a noção de cálculo relacional contribui para identificar as estratégias que explicitam os raciocínios envolvidos no campo aditivo.

A relevância desta pesquisa sustenta-se nos altos índices de evasão e repetência diagnosticados nos Cursos de Ciências Exatas (SILVA FILHO et al., 2007; CURY, 2008), e também, nas pesquisas desenvolvidas com crianças do Ensino Fundamental, que apontam as dificuldades inerentes ao campo aditivo, que podem constituir-se em barreiras para o desenvolvimento do pensamento matemático (MAGINA et al., 2008; SANTANA, 2010; VERGNAUD, 1982).

Ensinar pressupõe um claro entendimento das atuais competências e concepções do aluno, de suas competências quando ele era mais jovem e das competências que ele precisará ter quando for mais velho. Esta é uma consequência direta da teoria dos campos conceituais - herança do passado e preparação para o futuro (MAGINA et al., 2008, p. 12).

Nesse contexto, este trabalho contribui para a discussão acerca da importância da classificação da estrutura aditiva, tanto para a compreensão dos processos utiliza- 
dos na resolução das situações, quanto na identificação das dificuldades apresentadas pelos estudantes de Ensino Superior, em cada categoria.

\section{A Teoria dos Campos Conceituais}

Para Vergnaud (1993, p.1), a TCC preocupa-se com a formação e o desenvolvimento de conceitos, pois é "[...] uma teoria psicológica do conceito, ou melhor, da conceitualização do real, que permite situar e estudar as filiações e rupturas entre conhecimentos, do ponto de vista de seu conteúdo conceitual".

Segundo Pais (2008, p. 52), a TCC fornece subsídios ao professor para diagnosticar a aprendizagem e as dificuldades dos estudantes durante o processo de aquisição do conhecimento. Para Vergnaud (2009b), a formação e o desenvolvimento de um conhecimento conceitual devem emergir a partir de situações-problemas que levem em consideração a representação e o conceito.

A utilização adequada das situações-problemas auxilia o aluno na percepção das conexões existentes entre os vários conceitos. Com isto, o conhecimento passa ser concebido como uma sucessão de adaptações, em que o aluno realiza a partir de situações que vivencia na escola e na vida cotidiana (PAIS, 2008, p.53).

Para estudar a formação e o desenvolvimento de um conceito durante a aprendizagem dos educandos, Vergnaud (1993) define como uma terna de conjuntos $(S, I, Y)^{1}$, a saber:

$S$ conjunto das situações que dão sentido ao conceito (referência). I conjunto das invariantes em que se baseia a operacionalidade dos esquemas (significado). $Y$ conjunto das formas de linguagem (ou não) que permitem representar simbolicamente o conceito, suas propriedades, as situações e os procedimentos de tratamento (significante) (VERGNAUD, 1993, p.8).

As situações, os invariantes e as representações são conjuntos indissociáveis para a TCC, e para estudar o desenvolvimento e o funcionamento de um conceito durante os processos de ensino e aprendizagem é necessário considerar que estes três conjuntos ocorram simultaneamente. Entretanto, não podemos afirmar que há uma bijeção entre tais conjuntos, ou seja, não se pode reduzir o significado ao significante, nem às situações, e vice versa.

1. Utilizamos neste trabalho as nomenclatura (S, I, Y) para representar o terna de conjuntos das situações $-\mathrm{S}$, das invariantes $-\mathrm{I}$, e das representações $-\mathrm{R}$. Ressaltamos que podem ocorrer variações desta representação na literatura, como encontrado em Magina et al. (2008), na qual tem-se (S, I, R). Vergnaud (1996) também utiliza (S, I, s). 
Para uma classe de situações dada, o aluno tem várias decisões a tomar, e estas são também objeto de uma organização invariante. Magina et al. (2008) ressaltam que o conjunto dos invariantes compreende os objetos, as propriedades e as relações que podem ser reconhecidas e usadas pelo sujeito para analisar e dominar as situações, expressando a compreensão do educando sobre o conceito, por isso os invariantes dão significado ao conceito.

Os invariantes operatórios dividem-se em três tipos lógicos: proposição ou teoremas em ação, funções proposicionais ou conceitos em ação e argumento (VERGNAUD, 1993). Para atender os objetivos deste trabalho, focamo-nos sobre os teoremas em ação.

Os invariantes do tipo proposição, denominados teoremas em ação, são as relações matemáticas consideradas pelos alunos quando eles escolhem uma operação ou uma sequência de operações para resolver uma situação-problema dada. Os teoremas em ação são teoremas implícitos e têm validade local, ou seja, são verdadeiros apenas para um conjunto de situações. De maneira geral, este tipo de invariante é inconsciente, pois os alunos utilizam-no quando enfrentam situações-problemas, sem muitas vezes saber falar sobre o que estão usando.

Os teoremas em ação são considerados recursos para o professor analisar as estratégias dos alunos ao solucionarem uma situação-problema e, auxiliá-los na transformação do conhecimento implícito para o explícito.

Neste contexto, estabelecer classificações às situações-problemas, descrever procedimentos, formular teoremas-em-ação, analisar a estrutura e a função dos enunciados e das representações simbólicas é de interesse para a aprendizagem em Matemática (FRANCHI, 2010).

\section{O Campo Conceitual das Estruturas Aditivas}

O campo conceitual das estruturas aditivas é o conjunto de situações cujo domínio requer uma ou várias adições ou subtrações ou uma combinação de tais operações, e o conjunto dos conceitos e teoremas que permitem analisar estas situações como tarefas matemáticas (VERGNAUD, 1993).

Dominar as estruturas aditivas implica ser capaz de resolver diversos tipos de situações-problemas, o que significa que não basta saber operar um cálculo numérico. Para Vergnaud (2009b, p.199), há tipos variados de relações aditivas, o que implica cálculos relacionais de adições e subtrações diferentes.

As relações aditivas são relações ternárias que podem ser encadeadas de maneiras distintas e resultar em estruturas aditivas variadas. Este campo conceitual é classificado de acordo com os níveis de dificuldade das situações-problemas e o raciocínio requerido para resolvê-las. 
Esta classificação tem por objetivo oferecer uma estrutura teórica que auxilie o professor no entendimento do significado das diferentes representações simbólicas da adição e subtração, e de servir de base para o desenho de experiências sobre esses processos matemáticos em sala de aula. A razão teórica para as distinções na classificação é de origem tanto psicológica quanto matemática (MAGINA et al., 2008, p.19).

Os seis esquemas ternários fundamentais, classificados em categorias, que compõem o campo das estruturas aditivas, propostos por Vergnaud (2009b, p.200), são: primeira categoria - aquela em que duas medidas se compõem para resultar em uma terceira medida; segunda categoria - aquela em que uma transformação opera sobre uma medida para resultar em outra medida; terceira categoria - aquela em que uma relação estática liga duas medidas; quarta categoria - aquela em que duas transformações se compõem para resultar em uma transformação; quinta categoria - aquela em que uma transformação opera sobre um estado relativo (uma relação) para resultar em um estado relativo e sexta categoria - aquela em que dois estados relativos (relações) se compõem para resultar em um estado relativo.

Para facilitar a compreensão dos diferentes códigos utilizados para representar os esquemas da estrutura aditiva presentes nas seis categorias, apresentamos o Quadro 01 onde estão indicados os objetos e o que estes representam.

Quadro 01 - Símbolos utilizados para a representação do cálculo relacional

\begin{tabular}{|l|l|l|}
\hline Figura & Nome & Representa \\
\hline & Retângulo & $\begin{array}{l}\text { Uma medida, ou seja, um } \\
\text { número natural. }\end{array}$ \\
\hline & Elipse & $\begin{array}{l}\text { Uma transformação ou uma } \\
\text { relação, ou seja, um número } \\
\text { relativo. }\end{array}$ \\
\hline & Chave horizontal & $\begin{array}{l}\text { Composição de elementos de } \\
\text { mesma natureza. }\end{array}$ \\
\hline & Flecha horizontal & $\begin{array}{l}\text { Uma transformação ou uma } \\
\text { relação entre elementos de } \\
\text { mesma natureza. }\end{array}$ \\
\hline
\end{tabular}

Fonte: Vergnaud (2009b, p. 201). 
As legendas do Quadro 01 serão utilizadas na representação do cálculo relacional de cada um dos problemas, nas seis categorias.

\section{Percurso metodológico}

Para atender o objetivo desta pesquisa, iniciamos este trabalho com a elaboração de problemas das seis categorias da estrutura aditiva, conforme apresentado por Vergnaud (2009b), visando o público-alvo, a saber: os estudantes ingressantes nos Cursos de Ciências Exatas de uma universidade pública do interior do Paraná.

Encontramos na literatura exemplos de problemas das categorias que constituem o campo conceitual aditivo (VERGNAUD, 2009b; MAGINA et al., 2008), no entanto, estes são destinados às séries iniciais do Ensino Fundamental. Assim, na construção dos problemas, os autores consideraram o nível de escolaridade dos sujeitos envolvidos.

Para o teste foram selecionados seis problemas, ordenados segundo as categorias propostas por Vergnaud (2009b, p. 200), e aplicados, simultaneamente, a todas as turmas dos primeiros anos dos Cursos de Ciências, Estatística, Física, Matemática e Química, uma semana após o início do ano letivo de 2012. Aceitaram participar da pesquisa 309 estudantes destes cursos.

A seguir apresentaremos uma descrição dos problemas aplicados, ordenados segundo as categorias, o cálculo relacional envolvido, os resultados obtidos e os invariantes operatórios detectados nas respostas incorretas, com os respectivos exemplos ilustrativos.

Problema 1: Segundo o censo demográfico do Instituto Brasileiro de Geografia e Estatística (IBGE), em 2011, pela primeira vez no Brasil, os brancos são menos da metade da população total. Dos 190.755.799 habitantes registrados nesse ano, 99.697.545 declararam-se de cor negra, parda, amarela ou indígena. Quantos são os brancos?

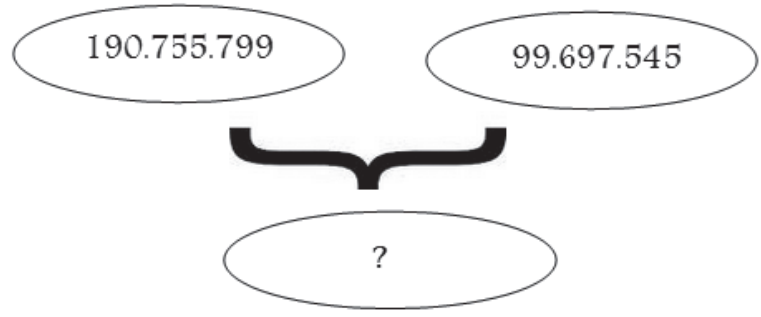


Cálculo relacional: Medida 1 (M1) $=190.755 .799 ;$ Medida $2($ M2) $=99.697 .545$ Composição: $M 1-M 2=91.058 .254$

Tabela 01: Resultados obtidos no Problema 1

\begin{tabular}{|c|c|c|c|c|c|c|}
\hline & \multicolumn{2}{|c|}{$\begin{array}{l}\text { Cálculo relacional } \\
\text { correto }\end{array}$} & \multirow{2}{*}{$\begin{array}{l}\text { Cálculo } \\
\text { relacional } \\
\text { errado ou } \\
\text { inadequado }\end{array}$} & \multicolumn{2}{|c|}{ Sem cálculo relacional } & \multirow{2}{*}{ Não fez } \\
\hline & $\begin{array}{l}\text { Resultado } \\
\text { correto }\end{array}$ & $\begin{array}{l}\text { Resultado } \\
\text { errado }\end{array}$ & & $\begin{array}{l}\text { Resultado } \\
\text { correto }\end{array}$ & $\begin{array}{l}\text { Resultado } \\
\text { errado }\end{array}$ & \\
\hline $\begin{array}{l}\text { Quantidade de } \\
\text { alunos }\end{array}$ & 218 & 60 & 5 & 18 & 5 & 3 \\
\hline $\begin{array}{l}\text { Porcentagem } \\
\text { de alunos }\end{array}$ & $70,55 \%$ & $19,3 \%$ & $1,62 \%$ & $5,82 \%$ & $1,62 \%$ & $1,09 \%$ \\
\hline
\end{tabular}

Fonte: Questionário

A maioria dos alunos, em torno de $90 \%$ do total, realizou o cálculo relacional correto deste problema, no entanto 60 estudantes apresentaram erros na operação M1 - M2, apesar de disporem de uma calculadora. Isso ocorreu em função de que a calculadora utilizada não comportava mais do que oito dígitos, o que obrigou os alunos a calcular manualmente. Segundo Vergnaud (2009b, p. 212), a ordem de grandeza da medida influencia no grau de complexidade do cálculo relacional. Se, por exemplo, as medidas fossem 190 e 100 milhões, a solução do problema seria mais fácil, tanto em função da subtração, quanto do procedimento envolvidos. $\mathrm{Na}$ Figura 01 é ilustrado um desses casos.

Figura 01: Cálculo relacional correto e resposta errada

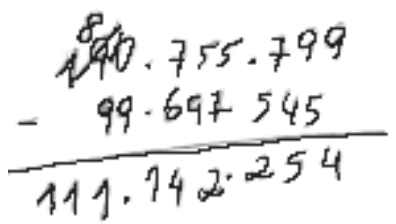

Fonte: Questionário

O problema 1 apresentou quatro tipos diferentes de cálculos relacionais inadequados, resultantes de teoremas em ação falsos mobilizados pelos estudantes. No Quadro 02 é apresentada uma breve descrição desses invariantes e suas consequências. 
Quadro 02: Invariantes operatórios detectados nas respostas incorretas do Problema 1.

\begin{tabular}{|c|c|c|}
\hline $\begin{array}{l}\text { Invariante } \\
\text { inadequado }\end{array}$ & \multicolumn{2}{|l|}{ Consequência } \\
\hline $\begin{array}{l}\text { Utilizou proporção } \\
\text { para estimar a } \\
\text { porcentagem } \\
\text { equivalente à } \\
\text { população de brancos }\end{array}$ & $\begin{array}{l}\text { Não conseguiu } \\
\text { calcular o resultado } \\
\text { final (Ex. 1a) }\end{array}$ & $\begin{array}{l}\text { Ex.1 } \\
\qquad \begin{array}{rl}190755799 x=9969754500 \\
x & =\frac{9969754500}{190755799} \\
-55 \% & x=55 \% \\
45 \% & R=B R \operatorname{Rancos} 45 \%\end{array}\end{array}$ \\
\hline $\begin{array}{l}\text { Dividiu o total que } \\
\text { foi declarado de } \\
\text { cor negra, parda, } \\
\text { amarela ou indígena, } \\
\text { (99.697.547), por } \\
\text { 3, indicando que } \\
\text { esses três grupos } \\
\text { estariam igualmente } \\
\text { distribuídos }\end{array}$ & $\begin{array}{l}\text { Não conseguiu chegar } \\
\text { numa resposta para a } \\
\text { população de brancos } \\
\text { (Ex. 1b) }\end{array}$ & 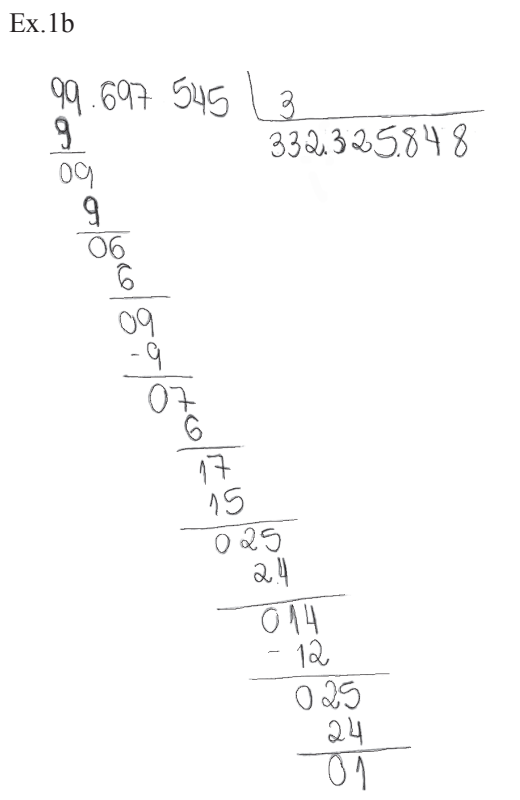 \\
\hline $\begin{array}{l}\text { Adicionou a M2 a } \\
\text { metade de M1 }\end{array}$ & $\begin{array}{l}\text { Não conseguiu obter } \\
\text { resposta coerente com } \\
\text { o problema (Ex. 1c) }\end{array}$ & $\begin{array}{l}\text { Ex.1c }(1) \frac{T}{2}+X=B \\
T=190.755 .799 \\
X=99697545 \\
B=\end{array}$ \\
\hline
\end{tabular}




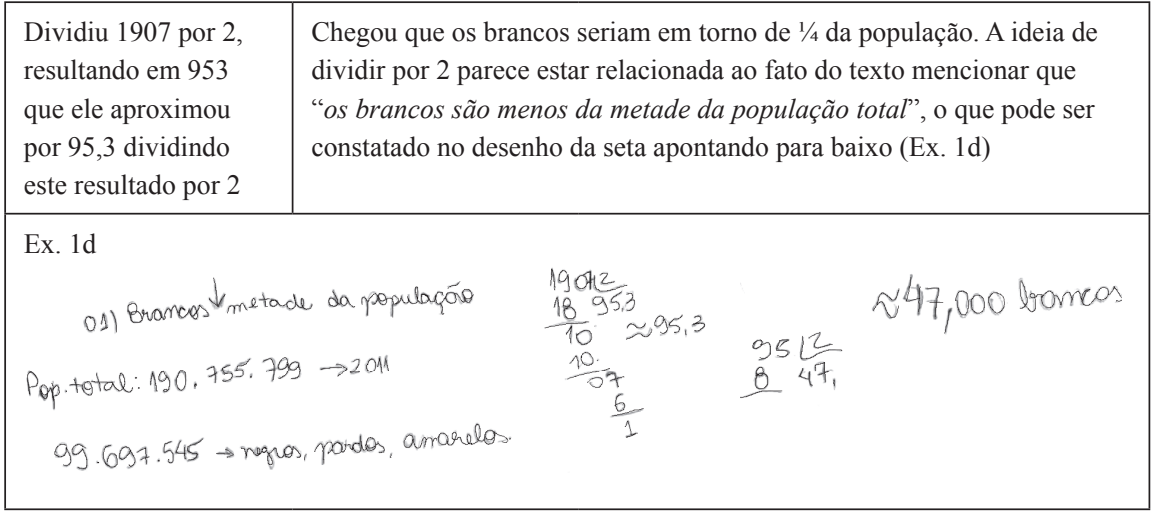

Fonte: Questionário

A ordem e a quantidade de informações apresentadas no Problema 1 influenciaram na sua complexidade, quanto aos dados que são necessários e suficientes para resolvê-lo. O Exemplo 1a ilustra esta situação, em que as informações "os brancos são menos da metade da população total" e "declararam-se de cor negra, parda, amarela ou indígena" influenciaram na resolução do problema. Fato este também destacado por Vergnaud (2009, p. 213) em relação aos problemas típicos apresentados na escola básica, em que apenas são fornecidas as informações essenciais à sua resolução.

Problema 2: João fará uma viagem de Maringá para Campo Grande no próximo sábado, partindo no Voo das 11h10min e chegará as 11h20min, hora local. Qual a duração prevista desta viagem, sabendo que o fuso horário de Campo Grande possui 1 h de atraso com relação ao de Maringá?

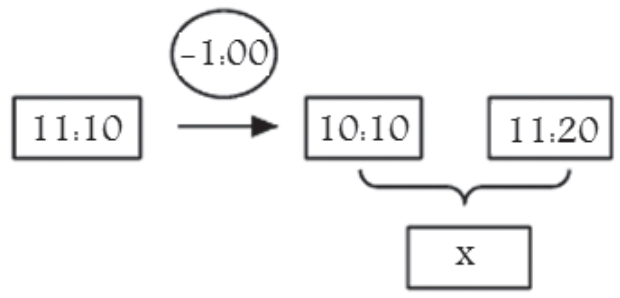

Cálculo relacional: Estado inicial (Ei) = 11h10min; Transformação $(T)=-1 \mathrm{~h}$; Estado final $($ Ef $)=11 \mathrm{~h} 20 \mathrm{~min}-(11 \mathrm{~h} 10 \mathrm{~min}-1 \mathrm{~h} 00 \mathrm{~min})=1 \mathrm{~h} 10 \mathrm{~min}$ 
Tabela 02: Resultados obtidos no Problema 2

\begin{tabular}{|c|c|c|c|c|c|c|}
\hline & \multicolumn{2}{|c|}{$\begin{array}{l}\text { Cálculo relacional } \\
\text { correto }\end{array}$} & \multirow{2}{*}{$\begin{array}{l}\text { Cálculo } \\
\text { relacional } \\
\text { errado ou } \\
\text { inadequado }\end{array}$} & \multicolumn{2}{|c|}{ Sem cálculo relacional } & \multirow{2}{*}{ Não fez } \\
\hline & $\begin{array}{l}\text { Resultado } \\
\text { correto }\end{array}$ & $\begin{array}{l}\text { Resultado } \\
\text { errado }\end{array}$ & & $\begin{array}{l}\text { Resultado } \\
\text { correto }\end{array}$ & $\begin{array}{l}\text { Resultado } \\
\text { errado }\end{array}$ & \\
\hline $\begin{array}{l}\text { Quantidade de } \\
\text { alunos }\end{array}$ & 165 & 6 & 20 & 90 & 25 & 3 \\
\hline $\begin{array}{l}\text { Porcentagem } \\
\text { de alunos }\end{array}$ & $53,4 \%$ & $1,94 \%$ & $6,47 \%$ & $29,13 \%$ & $8,09 \%$ & $0,97 \%$ \\
\hline
\end{tabular}

Fonte: Questionário

Neste problema, pouco mais da metade dos alunos, em torno de $55 \%$ do total, realizou o cálculo relacional correto. Este problema apresentou quatro tipos diferentes de cálculos relacionais inadequados, resultantes de teoremas em ação falsos. O Quadro 03 mostra uma breve descrição desses invariantes e suas consequências.

Quadro 03: Invariantes operatórios detectados nas respostas incorretas do Problema 2.

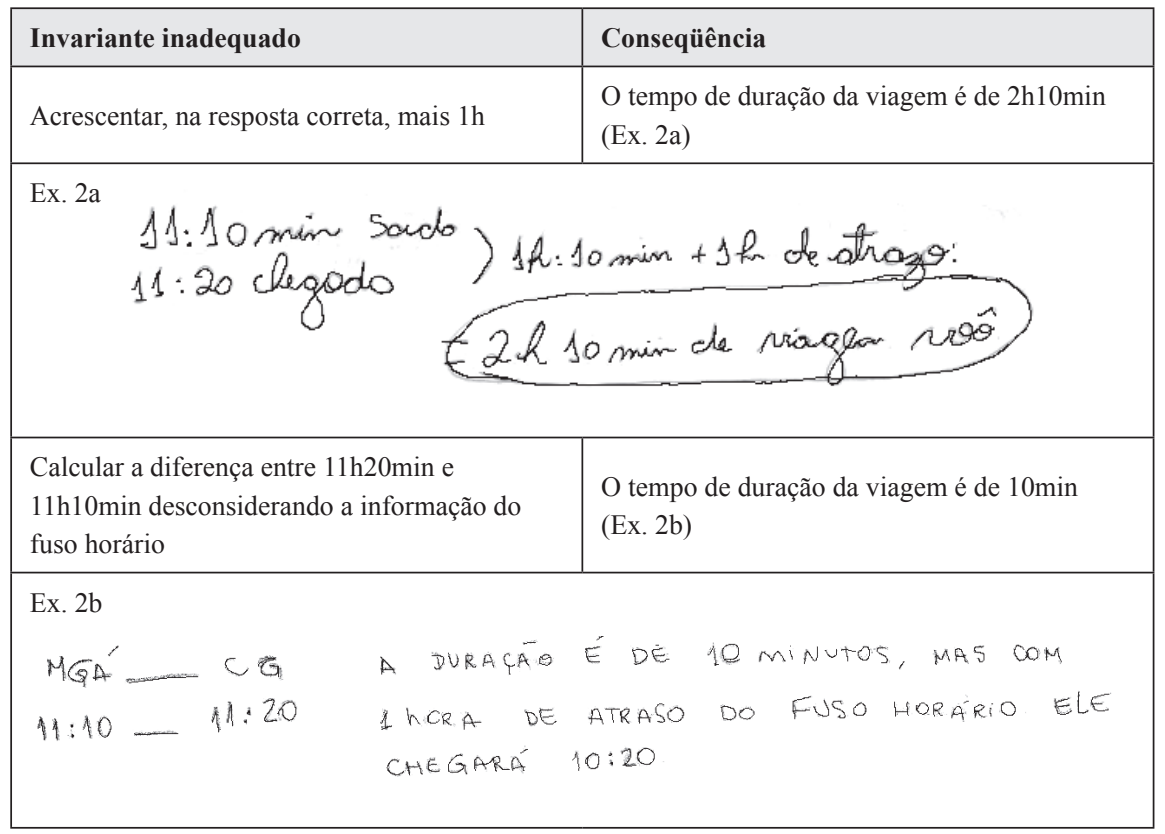


Considerar que a hora de chegada em Campo Grande, 11h20min, é a hora em Maringá e, portanto, em Campo Grande a hora local seria $10 \mathrm{~h} 20 \mathrm{~min}$
O tempo de duração da viagem é $11 \mathrm{~h} 10 \mathrm{~min}-$ $10 \mathrm{~h} 20 \mathrm{~min}=50 \mathrm{~min}($ Ex. 2c)

Ex. ${ }^{3}$

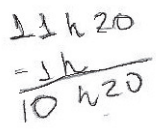

19 minivir in da chegada em campo Grande

Assumir que o fuso horário entre Maringá e

Campo Grande é de $24 \mathrm{~h}$

O tempo de duração de viagem é de $24 \mathrm{~h} 10 \mathrm{~min}$

(Ex. 2d)

Ex. $2 d$

$$
\begin{aligned}
& \text { 11:10-11:20 Ihara de atraso }
\end{aligned}
$$

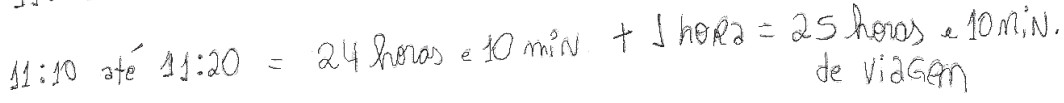

Problema 3: Carlos emprestou a Antonio $R \$ 300,00$. André também possui uma divida com Carlos, mas supera a divida de Antonio em $R \$ 250,00$. Qual a dívida de André?

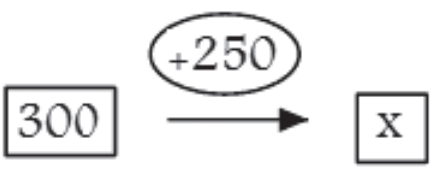

Cálculo relacional: Medida $1(M 1)=300$; Relação $(R)=+250$; Medida 2 (M2) $=M 1+R=550$

Tabela 3: Resultados obtidos no Problema 3

\begin{tabular}{|c|c|c|c|c|c|c|}
\hline & \multicolumn{2}{|c|}{$\begin{array}{l}\text { Cálculo relacional } \\
\text { correto }\end{array}$} & \multirow{2}{*}{$\begin{array}{l}\text { Cálculo } \\
\text { relacional } \\
\text { errado ou } \\
\text { inadequado }\end{array}$} & \multicolumn{2}{|c|}{ Sem cálculo relacional } & \multirow{2}{*}{ Não fez } \\
\hline & $\begin{array}{l}\text { Resultado } \\
\text { correto }\end{array}$ & $\begin{array}{l}\text { Resultado } \\
\text { errado }\end{array}$ & & $\begin{array}{l}\text { Resultado } \\
\text { correto }\end{array}$ & $\begin{array}{l}\text { Resultado } \\
\text { errado }\end{array}$ & \\
\hline $\begin{array}{l}\text { Quantidade de } \\
\text { alunos }\end{array}$ & 226 & 3 & 11 & 61 & 6 & 2 \\
\hline $\begin{array}{l}\text { Porcentagem } \\
\text { de alunos }\end{array}$ & $73,14 \%$ & $0,97 \%$ & $3,56 \%$ & $19,74 \%$ & $1,94 \%$ & $0,65 \%$ \\
\hline
\end{tabular}

Fonte: Questionário 
A maioria dos alunos realizou o cálculo relacional correto. O cálculo relacional inadequado, apresentado pelos alunos que erraram esta questão, indica apenas a diferença entre 300 e 250, ignorando-se os devedores, Antonio e André, e o credor, Carlos. A consequência deste invariante levou o aluno a responder que a divida de André é de $\mathrm{R} \$ 50,00$. A Figura 02 ilustra uma dessas respostas.

Figura 02: Invariante inadequado apresentado por um grupo de estudantes no Problema 3.
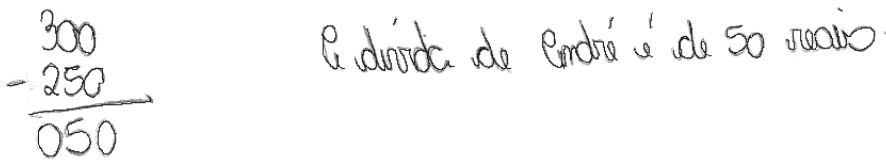

Fonte: Questionário

Problema 4: A mãe de Pedrinho colocou algumas laranjas numa cesta para ele levar à sua avó. No caminho, Pedrinho chupou cinco laranjas, mas ficou preocupado, assim parou no sitio do Senhor Raul e colheu mais laranjas. Ao chegar à casa de sua avó, contou as laranjas da cesta e percebeu que havia seis a mais do que a quantidade que sua mãe havia colocado pela manhã. Quantas laranjas Pedrinho pegou no sítio do Senhor Raul?

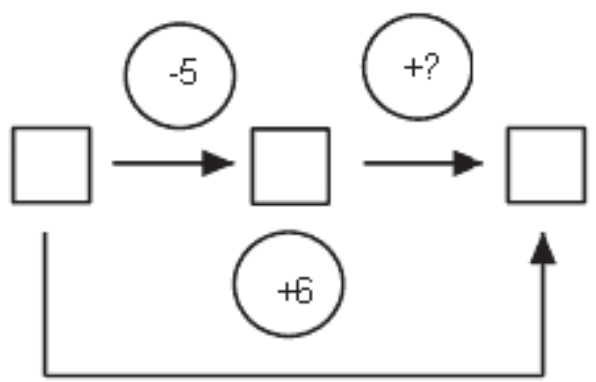

Cálculo relacional: Transformação $(T 1)=-5$; Transformação $(T 2)=$ desconhecida; Transformação $(T 3)=+6 ; T 1+T 2=T 3$ 
Tabela 4: Resultados obtidos no Problema 4

\begin{tabular}{|l|l|l|l|l|l|l|l|}
\hline & \multicolumn{2}{|l|}{$\begin{array}{l}\text { Cálculo relacional } \\
\text { correto }\end{array}$} & \multicolumn{2}{l|}{$\begin{array}{l}\text { Cálculo relacional } \\
\text { errado ou inadequado }\end{array}$} & \multicolumn{2}{l|}{ Sem cálculo relacional } & \multirow{2}{*}{ Não fez } \\
\cline { 2 - 6 } & $\begin{array}{l}\text { Resultado } \\
\text { correto }\end{array}$ & $\begin{array}{l}\text { Resultado } \\
\text { errado }\end{array}$ & $\begin{array}{l}\text { Resultado } \\
\text { correto }\end{array}$ & $\begin{array}{l}\text { Resultado } \\
\text { errado }\end{array}$ & $\begin{array}{l}\text { Resultado } \\
\text { correto }\end{array}$ & $\begin{array}{l}\text { Resultado } \\
\text { errado }\end{array}$ & \\
\hline $\begin{array}{l}\text { Quantidade } \\
\text { de alunos }\end{array}$ & 173 & 4 & 6 & 14 & 67 & 19 & 26 \\
\hline $\begin{array}{l}\text { Porcentagem } \\
\text { de alunos }\end{array}$ & $55,99 \%$ & $1,29 \%$ & $1,95 \%$ & $4,53 \%$ & $21,68 \%$ & $6,15 \%$ & $8,41 \%$ \\
\hline
\end{tabular}

Fonte: Questionário

Os invariantes inadequados apresentados neste problema podem ser classificados em três tipos: um que utiliza, nos cálculos, as cinco laranjas que Pedrinho chupou e as seis que ficaram a mais no final, outro relacionado à ausência da medida inicial e, o terceiro em que os estudantes tentam resolver o problema por meio de equações em uma variável.

Segundo Vergnaud (1982), a principal dificuldade apresentada, nesta categoria, está justamente na ausência da quantidade inicial, mesmo que esta seja irrelevante para obter a solução. No Quadro 04 é apresentada uma breve descrição desses invariantes e suas consequências.

Quadro 04: Invariantes operatórios detectados nas respostas incorretas do Problema 4.

\begin{tabular}{|c|c|c|}
\hline Invariante & \multicolumn{2}{|l|}{ Consequência } \\
\hline $\begin{array}{l}\text { Desconsiderar a } \\
\text { transformação inicial }\end{array}$ & $\begin{array}{l}\text { Pedrinho colheu } \\
6 \text { laranjas, que foi } \\
\text { a quantidade que } \\
\text { tinha a mais do que a } \\
\text { inicial (Ex. 1a) }\end{array}$ & 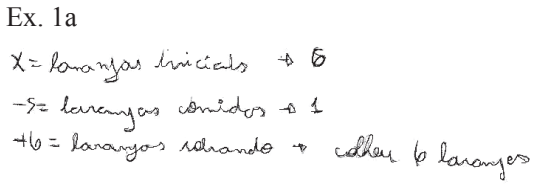 \\
\hline $\begin{array}{l}\text { Considerar que }+6 \text { é } \\
\text { a transformação que } \\
\text { compõe o resultado } \\
\text { final, quando na } \\
\text { verdade é o resultado } \\
\text { final }\end{array}$ & $\begin{array}{l}\text { Pedrinho colheu } \\
1 \text { laranja, pois ele } \\
\text { chupou } 5 \text { e chegou } \\
\text { com } 6 \text { a mais (Ex. 1b) }\end{array}$ & Ex. 1b \\
\hline
\end{tabular}




\begin{tabular}{|c|c|c|}
\hline $\begin{array}{l}\text { Utilizar a mesma } \\
\text { variável para } \\
\text { representar coisas } \\
\text { diferentes }\end{array}$ & $\begin{array}{l}\text { A quantidade de } \\
\text { laranjas que Pedrinho } \\
\text { colheu é representada } \\
\text { pela mesma variável } \\
\text { da quantidade inicial } \\
\text { de laranjas (Ex. 1c) }\end{array}$ & 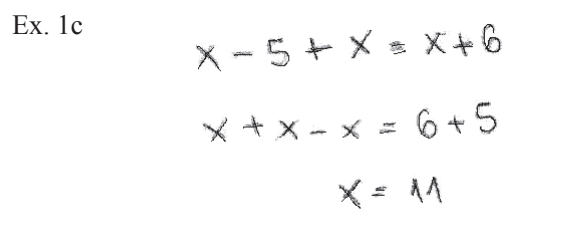 \\
\hline $\begin{array}{l}\text { Necessitar da quan } \\
\text { o problema }\end{array}$ & inicial para resolver & O problema não tem solução. Ex. 1d \\
\hline $\begin{array}{l}\text { Ex.1d } \\
\text { náo est } \\
\text { pegou }\end{array}$ & $\begin{array}{l}\text { th - Nás ha } \\
\text { xplicito a quo } \\
\text { nuo már as }\end{array}$ & $\begin{array}{l}\text { como sober a quantia, pois } \\
\text { tia de macas que pedrinho } \\
\text { sair }\end{array}$ \\
\hline $\begin{array}{l}\text { Considerar que a q } \\
\text { quantidade final }\end{array}$ & ade inicial é igual a & $\begin{array}{l}x-5=x+6 \text {, a quantidade de laranjas na } \\
\text { primeira transformação é igual ao resultado } \\
\text { final (Ex. 1e) }\end{array}$ \\
\hline \multicolumn{3}{|c|}{ wernjos } \\
\hline $\begin{array}{l}\text { Considerar que a q } \\
\text { quantidade inicial }\end{array}$ & ade final é igual a & $\begin{array}{l}\text { Pedrinho colheu } 5 \text { laranjas, a mesma } \\
\text { quantidade que chupou (Ex. 1f) }\end{array}$ \\
\hline \multicolumn{3}{|r|}{ 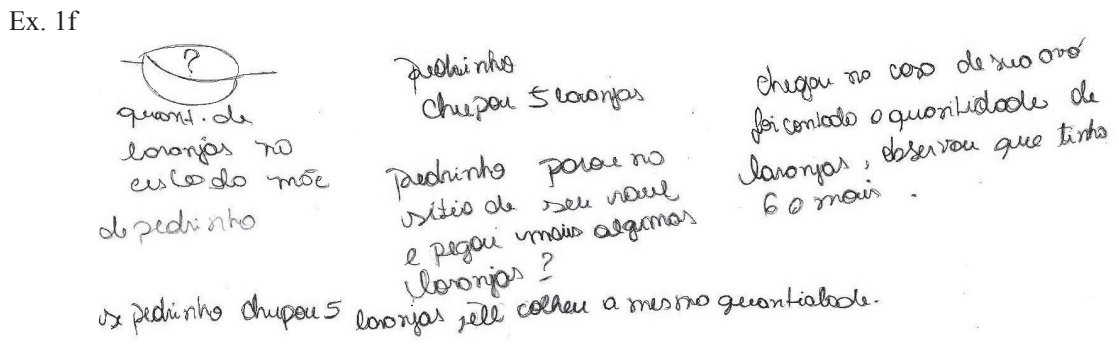 } \\
\hline
\end{tabular}

Fonte: Questionário

Problema 5: Qual é o saldo de uma equipe de basquete que marcou 230 pontos e sofreu 251 pontos? 


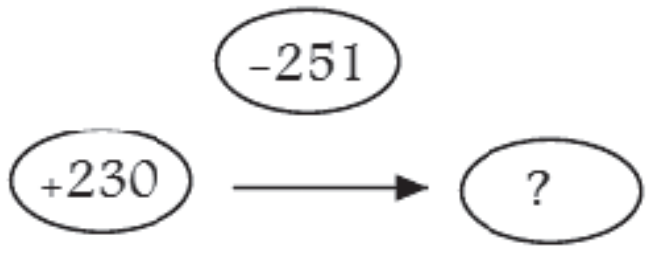

Cálculo Relacional: Estado Relativo $(R 1)=+230$; Transformação $(T 1)=-251$; Estado Relativo (R2) desconhecido; $R 1+T 1=R 2$

Tabela 5: Resultados obtidos no Problema 5

\begin{tabular}{|c|c|c|c|c|c|c|}
\hline & \multicolumn{2}{|c|}{$\begin{array}{l}\text { Cálculo relacional } \\
\text { correto }\end{array}$} & \multirow{2}{*}{$\begin{array}{l}\text { Cálculo } \\
\text { relacional } \\
\text { errado ou } \\
\text { inadequado }\end{array}$} & \multicolumn{2}{|c|}{ Sem cálculo relacional } & \multirow{2}{*}{ Não fez } \\
\hline & $\begin{array}{l}\text { Resultado } \\
\text { correto }\end{array}$ & $\begin{array}{l}\text { Resultado } \\
\text { errado }\end{array}$ & & $\begin{array}{l}\text { Resultado } \\
\text { correto }\end{array}$ & $\begin{array}{l}\text { Resultado } \\
\text { errado }\end{array}$ & \\
\hline $\begin{array}{l}\text { Quantidade de } \\
\text { alunos }\end{array}$ & 172 & 23 & 26 & 57 & 19 & 12 \\
\hline $\begin{array}{l}\text { Porcentagem } \\
\text { de alunos }\end{array}$ & $55,67 \%$ & $7,44 \%$ & $8,41 \%$ & $18,45 \%$ & $6,15 \%$ & $3,88 \%$ \\
\hline
\end{tabular}

A maioria dos estudantes não encontrou dificuldades na resolução deste problema, e as respostas incorretas foram decorrentes do seguinte invariante inadequado: o saldo é sempre positivo. Deste invariante resultaram quatro tipos de respostas incorretas: alguns estudantes responderam que: "a equipe de basquete não tem saldo porque ela sofreu mais pontos do que marcou"; outro grupo apresentou o seguinte cálculo: $251-230=+21$, respondendo que o saldo é 21 pontos positivos; um estudante respondeu que o saldo da equipe é 230 pontos porque os pontos sofridos não interferem no saldo; e, ainda um estudante fez o cálculo relacional correto, com resultado correto, no entanto respondeu que o saldo da equipe é zero.

Segundo Vergnaud (2009b, p. 214), para as crianças, as noções de "ganhar" ou "perder" bolinhas e "ganhar" ou "perder" pontos, por exemplo, referem-se a níveis diferentes de dificuldades por remeterem a noções de referências (bolinhas e pontos) diferentes.

No problema 5, as informações "marcou 230" e "sofreu 251" tratam de um nível de abstração diferente do que "tenho 230" e "devo 251" o que significaria que "devo ainda 21". Para alguns estudantes, a equipe não poderia ter saldo negativo de 21 pontos na partida. O Quadro 05 apresenta uma descrição desses invariantes. 
Quadro 05: Invariantes operatórios detectados nas respostas incorretas do Problema 5.

\begin{tabular}{|c|c|c|}
\hline $\begin{array}{l}\text { Invariante } \\
\text { inadequado }\end{array}$ & Consequências & Exemplo \\
\hline \multirow{4}{*}{$\begin{array}{l}\text { Considerar } \\
\text { que saldo é } \\
\text { positivo }\end{array}$} & $\begin{array}{l}\text { A equipe não tem } \\
\text { saldo }\end{array}$ & A esoquipe rais persui salds de pontos, pais sopten mais que mareou. \\
\hline & $\begin{array}{l}\text { O saldo da } \\
\text { equipe é }+21\end{array}$ & $\frac{251}{021 \rightarrow p 0 \operatorname{tos}}$ \\
\hline & $\begin{array}{l}\text { O saldo da } \\
\text { equipe é zero }\end{array}$ & 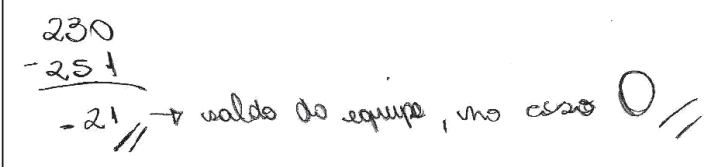 \\
\hline & $\begin{array}{l}\text { O saldo da } \\
\text { equipe é } 230\end{array}$ & 230 partos, prongue os pertes reficles näo interperem no valdo \\
\hline
\end{tabular}

Fonte: Questionário

Problema 6: Firisbrino tem um imóvel em Orticária e deve $R \$ 1.230,00$ de IPTU (Imposto Territorial Urbano) para a prefeitura desta cidade, que por sua vez tem uma divida trabalhista com Firisbrino de $R \$ 345,00$. Se a divida trabalhista puder ser utilizada para o abatimento no valor do IPTU, qual a divida de Firisbrino com a prefeitura?

Cálculo relacional: Estado relativo $(R 1)=-1230$; Estado relativo $(R 2)=+345$; Estado relativo $(R 3)=-885 ; R 1+R 2=R 3$

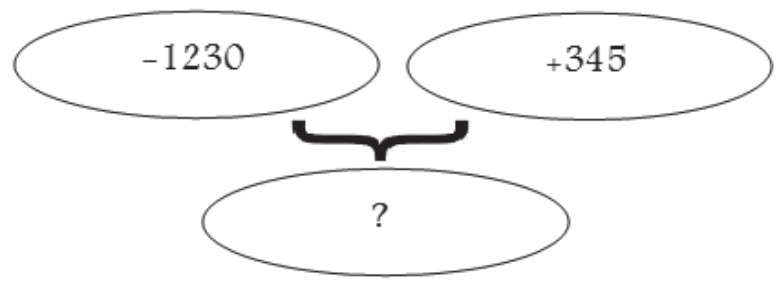


Tabela 6: Resultados obtidos no Problema 6

\begin{tabular}{|c|c|c|c|c|c|c|}
\hline & \multicolumn{2}{|c|}{$\begin{array}{l}\text { Cálculo relacional } \\
\text { correto }\end{array}$} & \multirow{2}{*}{$\begin{array}{l}\text { Cálculo } \\
\text { relacional } \\
\text { errado ou } \\
\text { inadequado }\end{array}$} & \multicolumn{2}{|c|}{ Sem cálculo relacional } & \multirow{2}{*}{ Não fez } \\
\hline & $\begin{array}{l}\text { Resultado } \\
\text { correto }\end{array}$ & $\begin{array}{l}\text { Resultado } \\
\text { errado }\end{array}$ & & $\begin{array}{l}\text { Resultado } \\
\text { correto }\end{array}$ & $\begin{array}{l}\text { Resultado } \\
\text { errado }\end{array}$ & \\
\hline $\begin{array}{l}\text { Quantidade de } \\
\text { alunos }\end{array}$ & 239 & 33 & 2 & 21 & 6 & 8 \\
\hline $\begin{array}{l}\text { Porcentagem } \\
\text { de alunos }\end{array}$ & $77,35 \%$ & $10,68 \%$ & $0,65 \%$ & $6,79 \%$ & $1,94 \%$ & $2,59 \%$ \\
\hline
\end{tabular}

Fonte: Questionário

Os alunos não apresentaram dificuldades no cálculo relacional correto para este problema, embora alguns, aproximadamente 11\% erraram a subtração. Apenas dois alunos apresentaram um cálculo relacional inadequado em que eles computaram as duas dívidas para Firisbrino (Quadro 06).

Quadro 06: Invariantes operatórios detectados nas respostas incorretas do Problema 6.

\begin{tabular}{|c|c|c|}
\hline $\begin{array}{l}\text { Invariante } \\
\text { inadequado }\end{array}$ & Consequência & Exemplo \\
\hline $\begin{array}{l}\text { Somar as dívidas, } \\
\text { independente de } \\
\text { quem deve. }\end{array}$ & $\begin{array}{l}\text { Firisbrino tem uma } \\
\text { dívida de } \mathrm{R} \$ 1.575,00 \\
\text { com a prefeitura }\end{array}$ & $\begin{array}{l}1230,00 \\
1345,00 \\
1575,00\end{array}$ \\
\hline
\end{tabular}

Fonte: Questionário

\section{Considerações Finais}

Esta pesquisa objetivou identificar os invariantes operatórios inadequados, apresentados por um grupo de estudantes, ingressantes nos Cursos de Ciências Exatas, em problemas do Campo Conceitual Aditivo.

A análise das resoluções obtidas no teste aplicado apontou alguns invariantes inadequados, apresentados pelos estudantes, em problemas de composição, transformação e comparação, os quais estão descritos no Quadro 07. 
Quadro 07: Síntese das resoluções apresentadas.

\begin{tabular}{|l|l|l|l|}
\hline Categoria & Problema & $\begin{array}{l}\text { Raciocínio } \\
\text { envolvido }\end{array}$ & $\begin{array}{l}\text { Principais invariantes inadequados } \\
\text { apresentados pelos estudantes }\end{array}$ \\
\hline \multirow{3}{*}{ Composição } & P1 & $\begin{array}{l}\text { Composição de } \\
\text { medidas }\end{array}$ & $\begin{array}{l}\text { Assumir que as classes (brancos, negros, } \\
\text { pardos, amarelos ou indígenas) que compõem } \\
\text { as medidas estão igualmente distribuídas }\end{array}$ \\
\cline { 2 - 4 } & P4 & $\begin{array}{l}\text { Composição de } \\
\text { transformação }\end{array}$ & $\begin{array}{l}\text { Entender que a quantidade inicial é condição } \\
\text { necessária para resolver o problema, e desta } \\
\text { forma assumir que a quantidade inicial é igual } \\
\text { a final }\end{array}$ \\
\cline { 2 - 5 } & P6 & $\begin{array}{l}\text { Composição de } \\
\text { relação }\end{array}$ & $\begin{array}{l}\text { Compor os valores do problema independente } \\
\text { das relações das quais eles derivam }\end{array}$ \\
\hline \multirow{2}{*}{ Transformação } & P2 & $\begin{array}{l}\text { Transformação } \\
\text { de medidas }\end{array}$ & $\begin{array}{l}\text { Compor os valores do problema sem a correta } \\
\text { transformação destes }\end{array}$ \\
\cline { 2 - 5 } & P5 & $\begin{array}{l}\text { Transformação } \\
\text { de relações }\end{array}$ & $\begin{array}{l}\text { Não identificar a transformação (saldo) } \\
\text { decorrente das duas relações ("sofreu” e } \\
\text { "marcou”) }\end{array}$ \\
\hline \multirow{2}{*}{ Comparação } & P3 & $\begin{array}{l}\text { Comparação de } \\
\text { medidas }\end{array}$ & $\begin{array}{l}\text { Não identificar o referencial (a dívida com } \\
\text { Carlos) para comparar as medidas (300 e 550) }\end{array}$ \\
\hline
\end{tabular}

Fonte: Questionário.

Cabe ressaltar que outros trabalhos como, por exemplo, os realizados por: Magina et al. (2008), com crianças brasileiras das séries iniciais; Santana (2010), com alunos da $3^{\mathrm{a}}$ série $/ 4^{\circ}$ ano do Ensino Fundamental, e Vergnaud (1982), com crianças francesas da escola elementar, também investigaram as estratégias e dificuldades, detectadas na resolução de situações-problemas da estrutura aditiva.

No entanto, não temos conhecimento de trabalhos, desta natureza, com estudantes universitários. A relevância desta pesquisa extrapola a quantificação dos acertos ou erros, além do que em todos os problemas, o número de acertos foi maior do que o de erros, almejando a identificação de possíveis causas para as dificuldades enfrentadas pelos estudantes nas disciplinas básicas dos Cursos de Ciências Exatas.

Tais dificuldades, também foram foco de estudo do trabalho de Cury (2008), em que foram analisados e classificados os erros apresentados pelos alunos ingressantes nos Cursos de Ciências Exatas, visando à superação dessas dificuldades por meio do desenvolvimento de estratégias de ensino.

É possível afirmarmos que alguns invariantes inadequados, aqui apresentados, também se mostram presentes nos erros detectados por Cury (2008). 
Dessa forma, podemos inferir que os invariantes inadequados apresentados no Quadro 07 podem prevalecer, nos estudantes, durante toda vida escolar. Por isso, a importância de proporcionar contatos com diversas situações que envolvem o mesmo conceito. Segundo Vergnaud (1993), quando o sujeito está frente a uma nova situação, mobiliza o conhecimento desenvolvido anteriormente e tenta adaptá-lo.

Finalmente, concordamos com Vergnaud (1990), quando afirma que as ideias de filiação e ruptura, necessárias para a compreensão de um conceito, ocorrem da mesma forma nas crianças e nos adultos e, nestes últimos, isto acontece mais pelos hábitos e experiências adquiridas do que pelo desenvolvimento da estrutura cognitiva.

\section{Referências}

CURY, Helena Noronha. Análise de erros: o que podemos aprender com as respostas dos alunos. $1^{\mathrm{a}}$ edição. $1^{\mathrm{a}}$ reimpressão. Belo Horizonte: Autêntica, 2008.

FRANCHI, Anna. Considerações Sobre a Teoria dos Campos Conceituais. In: MACHADO, SILVIA DIAS ALCÂNTARA MACHADO. Educação Matemática: Uma Nova Introdução. $3^{\text {a }}$ edição. São Paulo: EDUC, 2010.

MAGINA, Sandra; CAMPOS, Tânia Maria Mendonça; GATIRANA, Verônica. Repensando Adição e Subtração: Contribuições da Teoria dos Campos Conceituais. $3^{\mathrm{a}}$ edição. São Paulo: PROEM, 2008.

PAIS, Luiz Carlos. Didática da Matemática: Uma Análise da Influência Francesa. $2^{\mathrm{a}}$ ed. Belo Horizonte: Autêntica, 2008.

SANTANA, Eurivalda Ribeiro dos Santos. Estruturas Aditivas: O Suporte Didático Influência a Aprendizagem do Estudante? Tese apresentada ao Doutorado em Educação Matemática da Universidade Pontifícia Católica de São Paulo. São Paulo: PUC, 2010.

SILVA FILHO, Roberto Leal Lobo et. al.. A evasão no ensino superior brasileiro. Cadernos de Pesquisa, São Paulo, v. 37, n. 132, p. 641-659, 2007.

VERGNAUD, Gérard. A Classification of cognitive tasks and operations of thought involved in addition and subtraction problems in: CARPENTER, $T$. P., MOSER, J. M.; ROMBER, T. A. (Eds.) Addition and subtraction: a cognitive perspective. Hillsdale, NJ: Lawrence Erlbaum, p. 39-59, 1982. 
VERGNAUD, Gérard. La teoría de los campos conceptuales. Recherches en Didáctique des Mathématiques, Vol. 10,nº 2, 3, pp. 133-170, 1990.

VERGNAUD, Gérard . Teoria dos Campos Conceituais. In: Anais do $\mathbf{1}^{0}$ Seminário Internacional de Educação Matemática do Rio de Janeiro, 1993, UFRJ. Rio de Janeiro: Projeto Fundão - Instituto de Matemática - UFRJ, p. 1-26, 1993.

VERGNAUD, Gérard. A Teoria dos Campos Conceptuais. In: BRUN, JEAN. Didáctica das Matemáticas. Tradução: Maria José Figueiredo. Lisboa: Instituto Piaget - Horizontes Pedagógicos, p. 155-191, 1996.

VERGNAUD, Gérard. The Theory of Conceptual Fields. In: Human Development. Vol. 52, $\mathrm{n}^{\circ}$ 2. Printed in Switzerland: Karger, p. 83-94. Acesso on line: <www.karger. com/hde>, 2009a.

VERGNAUD, Gérard. A Criança, a Matemática e a Realidade: Problemas do Ensino da Matemática na Escolar Elementar. Tradução de Maria Lucia Faria Moro; Revisão técnica Maria Tereza Carneiro Soares. Curitiba: Editora da UFPR, 2009 b.

Submetido em outubro de 2012 Aprovado em dezembro de 2012 